Send your letters to the Editor, British

Dental Journal, 64 Wimpole Street, London

W1G8YS E-mail bdj@bda.org

Priority will be given to letters less than 500

words long. Authors must sign the letter,

which may be edited for reasons of space.

\section{World's worst teeth}

Sir, I travelled recently to the island of Mindoro in the Philippines with the Scientific Exploration Society who were researching an almost extinct buffalo, the Tamaraw.

Taking along a dental kit, I was able to treat some of the local indigenous population, the Mangyans, and performed almost exclusively extractions. On one particular day I went to a lower tribal Mangyan village (as opposed to the uplands) where I treated 14 patients, and recorded their dentition accordingly.

I was struck by a number of features. Firstly, a lot of the population are betel nut chewers and often smoke as well. Secondly, the dentition is fairly poor with a high decay rate, which I believe is due mainly to poor living conditions.

Six months ago a charity-based organisation built a water supply system for the villagers, who live in huts, originally from a spring some distance away.

The villagers had been brushing their teeth with sticks and sand and, as our group had brought toothbrushes and toothpaste, we were able to demonstrate correct brushing techniques.

In general, the Filipino population have the worst teeth in the world and have a high rate of oral cancer.

We felt we contributed in a small way to the improvement of oral health of the village and we intend returning again to monitor this; only recently there was a donation of a dental chair to the village, which is a beginning.

M. Lynch

Twickenham

doi: 10.1038/bdj.2007.645

\section{Soothing alternatives}

Sir, I wish to comment on Professor K. Mahalinga Bhat's letter on the action of cumin seeds which are a non-harmful remedy in the treatment of mouth ulcers: Fruit for ulcers (BDJ 2006; 201: 323). The points stated by the author are very true. I was suffering from recurrent aphthous ulcers for a long time and noticed that soaking these cumin seeds in warm water and later chewing them had a soothing effect, provided symptomatic relief and brought about quicker healing. I agree with the author that studies need to be conducted regarding the exact mode of action of these fruit grains.

I also wish to suggest a few treatment modalities which are used here in the Indian subcontinent that have proven to be effective in the treatment of RAU.

The use of herbs may be helpful; among these, liquorice that has had the glycyrrhizic acid removed and is called deglycyrrhizinated liquorice (DGL). This increases blood pressure and water retention in some people and may shorten the healing time. Aloe has also been shown to hasten the healing time and the antiviral and immunityenhancing drug Echinacea has been shown to provide relief. Camomile tincture is known to have a soothing effect on mouth ulcers, and there are certain astringent herbs which contain tannin and bind up inflammation, including agrimony, cranesbill, periwinkle and witch hazel.

An incision biopsy performed on a large ulcer is also said to hasten healing; the mode of action is unknown!

The sodium lauryl sulphate present in toothpaste which acts as a detergent impedes healing of mouth ulcers as it has a denaturing effect on the oral mucin layer with exposure of the underlying epithelium and results in an increased incidence of RAU. Hence toothpastes containing SLS should be used with caution while RAU is being symptomatically treated. The use of herbal toothpastes which do not have an aggravating effect is recommended. The other treatment modalities of RAU, like those stated above, should also be studied rather than being limited to the conventional method of treatment with its many side effects.

Meghashyam Bhat

Manipal

doi: $10.1038 /$ bdj.2007.646

\section{Clarification}

Sir, I write in response to the letter Orthodontic restrictions (BDJ 2007; 202: 510). Although many practitioners have concerns over the restriction on

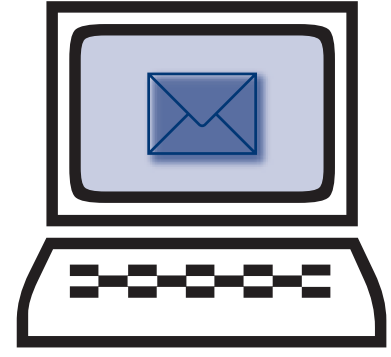

orthodontic treatment as a result of the new NHS dental contract, I would like to highlight a few points in relation to this letter.

The author states that 'Young patients who have been on a waiting list of up to two years... no longer can have their teeth straightened on the NHS... may have $5 \mathrm{~mm}$ overjets or malaligned upper or lower anterior teeth... and may suffer early trauma to upper anterior teeth... and also subject these young people to a lifetime of periodontal treatment when lower anteriors are overcrowded.'

Many patients referred for orthodontic consultations can wait considerably long times to be then told they fall below the IOTN cut off and therefore are not eligible for NHS funded treatment. However, it should be the referring practitioner's duty to be calibrated in the use of orthodontic indices so that an appropriate referral is being made in the first place. Therefore, even if the practitioner feels the patient falls below the IOTN threshold but a request for referral is still made, the patient can be aware from the outset that orthodontic treatment may subsequently be refused on the grounds of low need.

I would point out that patients presenting with a $5 \mathrm{~mm}$ overjet and incompetent lips may still be eligible for NHS treatment if the Aesthetic Component of the IOTN registers 6 or more. However, as the risk of trauma to upper incisors has been shown to increase to $45 \%$ for children with an overjet of greater than $9 \mathrm{~mm},{ }^{1}$ these malocclusions score a Dental Health Component of 5, indicating great need.

With regard to periodontal disease and lower anterior crowding, evidence is conflicting. Some studies have found no association between crowded teeth and periodontal destruction. ${ }^{2}$ Others have shown that malaligned teeth may have more plaque retention than straight teeth but socio-economic group, gender, tooth side and tooth surface have greater influences. ${ }^{3}$

Orthodontic treatment does not guarantee stability of the lower labial segment ${ }^{4}$ and lower incisor crowding may 
not indicate a lifetime of periodontal treatment if adequate oral hygiene is maintained.

\section{H. Popat}

Cardiff

1. Todd J, Dodd T. Children's dental health in the United Kingdom. London: Office of Population Census and Surveys, 1985.

2. Geiger A, Wasserman B, Turgeon L. Relationship of occlusion and periodontal disease. 8. Relationship of crowding and spacing to periodontal destruction and gingival inflammation. J Periodonto/ 1974; 45: 43-49.

3. Davies T, Shaw W, Worthington $\mathrm{H}$ et al. The effect of orthodontic treatment on plaque and gingivitis. Am J Orthod Dentofacial Orthop 1988; 93: 423-428.

doi: $10.1038 /$ bdj.2007.647

\section{Hot potato speech}

Sir, we would like to share with your readers an exceptional case of dental calculus which caused speech impairment mimicking a flaccid dysarthria due to immobility of the tongue.

A 46-year-old female patient presented complaining of a lump in her mouth. She exhibited an element of 'hot potato speech' although this was not a complaint. Her medical history was unremarkable and she was not a regular dental attender.

On examination there was extensive lingual and buccal mandibular arch supragingival calculus, which extended from the lower right second premolar area across the midline to the lower left first molar (Figs 1-2). The calculus restricted the movement of her tongue and was grooved on the superior surface by her tongue. Calculus was also evident on the occlusal surface of her maxillary teeth. Buccal marginal gingivitis was evident in the mandibular arch. Interestingly the maxillary teeth exhibited labial/buccal cervical abrasion lesions. The patient reported that she did brush her teeth once daily.

The supragingival calculus was removed using an ultrasonic scaler. After removal of the calculus the lower premolars were grade II mobile and the lower incisors were grade I mobile. The underlying floor of mouth mucosa appeared healthy and there were occlusal discrepancies where the supragingival calculus had formed the occlusal surfaces (Figs 3-4).

Upon immediate removal of the supragingival calculus the patient's speech was unaltered. Unfortunately this patient did not attend for follow up.

Dysarthria and apraxia of speech are common motor disorders with numerous neuromuscular causes. ${ }^{1}$ They may be mimicked by a number of physical alterations to the oral cavity without neurological impairment, from poorly-fitting dentures to anatomical changes following surgery. ${ }^{2}$ Although this patient's calculus was exceptional this case highlights the relevance of oral disorders in the aetiology of speech impairment.

L. M. Carter, Leeds

I. Varley, Wakefield

1. Kent R D, Kim Y J. Toward an acoustic typology of motor speech disorders. Clin Linguist Phon 2003; 17: 427-445.

2. Seifert $E$, Runte $C$, Riebandt $M$ et al. Can dental prostheses influence vocal parameters? J Prosthet Dent 1999; 81: 579-585.

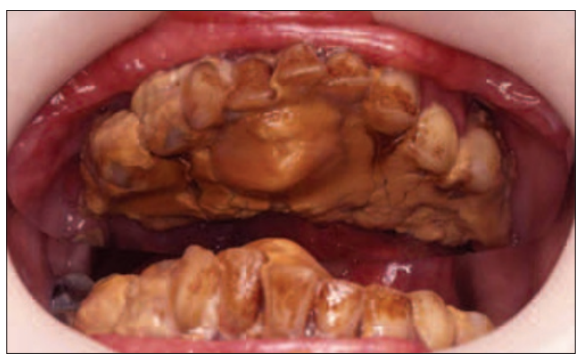

Fig. 1 Mirror view of extensive sublingual calculus

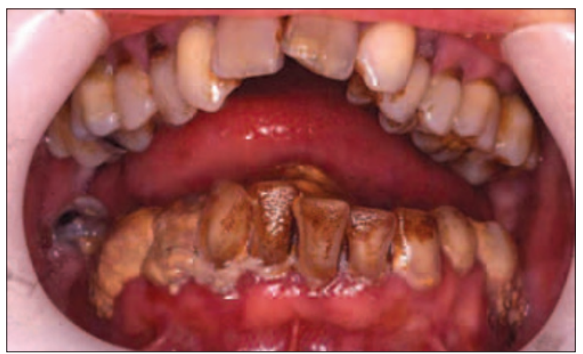

Fig. 2 Anterior view before calculus removal

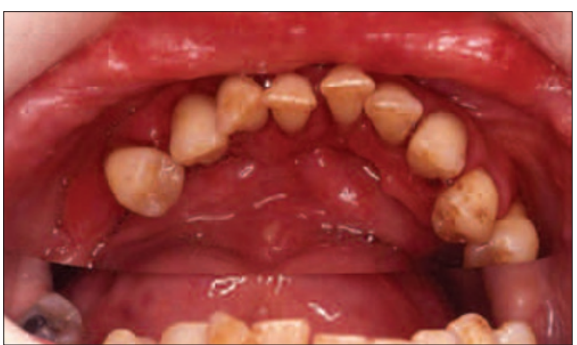

Fig. 3 Mirror view of floor of mouth after calculus removal

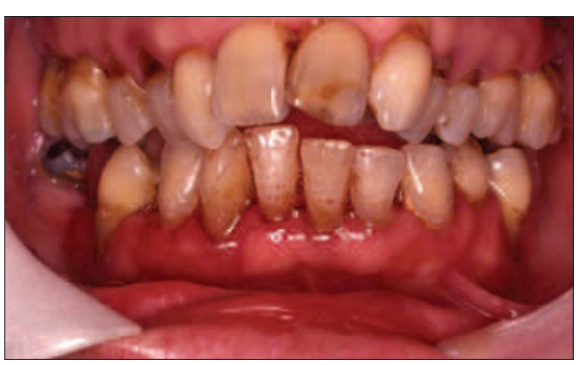

Fig. 4 Occlusion after calculus removal

doi: $10.1038 /$ bdj.2007.648

\section{Potential annihilation}

Sir, following the Chief Dental Officer's warning about the significant risk of transmitting vCJD by reusing endodontic instruments, it occurred to me that as this is such a risk and that the new Prime Minister Gordon Brown recently had endodontic treatment prior to the guidelines being issued, then surely it is too great a risk that the person whose finger is on the nuclear button could have vCJD.

I suppose it's a matter of considering the risk of an as yet unproved mode of transmission, but if this is accepted as the CDO asks, then we must therefore consider universal annihilation as a potential sequela. I'm sure once this has been explained to Gordon Brown he will step aside.

Has George Bush had endodontic treatment?

\section{Harbour}

Sandbach

doi: 10.1038/bdj.2007.649

\section{Behavioural confounders}

Sir, although I do not normally discuss my abstracts page in these columns, I cannot let pass my old friend Dr John Ahearne's letter (BDJ 2007; 202: 582) referring to my apparent bias. Dr Ahearne believes that I only 'abstract the papers that show no association' between periodontitis and systemic health. I don't at all mind being called biased, but I do prefer the charge to be evidence-based.

In the interests of my own education, I made a quick count of the relevant abstracts in 2006 and 2007 up to the date of Dr Ahearne's letter. Here are the results: there were six papers in favour and six against. There were five in favour of a periodontitis/cardiovascular association, and one for a respiratory relationship with plaque. There were two against a periodontitis-causingdiabetes association (one a meta-analysis by proponents of the association), and four against a pregnancy association (except possibly for late miscarriage), including the recent large intervention study in the New England Journal of Medicine.

In addition, there was a classic paper relating flossing habits to BMI, which the authors took to be a spurious association and used as an illustration of confounding factors! There were also two papers for a possible endodontic/ cardiovascular association.

If I may be permitted to say so, this whole area suffers from severe effects of behavioural confounders, to which I have sometimes referred in the abstracts. My personal bias is to reject most of the proposed associations until there is better evidence for them, but I try to abstract some of the more 
interesting papers I find on both sides. I fully agree with Professor Hughes, who started this correspondence.

\section{T. Watts}

London

doi: 10.1038/bdj.2007.650

\section{Safety and security}

Sir, all GDC registrants have their addresses displayed on the GDC's website. The role of the GDC is to protect the patients and the background is that patients need to be able to contact their registrants. Until recently, this was only available as hard copy in the Dentists Register but this was abolished last year.

There is a safety and security issue with this, eg with respect to a patient who may take a fancy to a member of staff and be in a position to pester her/ him at home, identity theft etc.

The Governance Department at my PCT advised me of the following, 'The GDC has two legal obligations which may be interpreted by them in a conflicting manner. First, their Administration of Core Functions Rules 2003 require the "Registered Address" to be recorded. Second, Data Protection Act 1998 (DPA) allows a dentist to request that the GDC stops processing personal data, such as not publishing the address. DPA does not require the GDC to comply with such a request, but it must consider it and give such a good reason for non-compliance - such as a significant public interest

- that will stand up in court.

The GDC has a DPA duty to ensure that it holds an accurate register, and it needs some method of identifying, for instance, the 230 separate dentists called Smith. A court and the Information Commissioner would probably judge it to be reasonable for the registered address to be used to do this. In order to ensure privacy it would be logical for the GDC to hold both the work address and the home address for each registrant, and for the work address to be used in the public arena. This is common practice throughout the NHS.'

The General Medical Council also has this obligation, but they do not display their registrants' addresses, asking them instead to display their unique GMC number wherever possible, eg on letterheads, ID badges, email and handwritten signatures etc. Their document ${ }^{1}$ recognises the sign of the times and deems using other methods for contact, such as PO Box number, as of little value as identifiers.

The General Optical Council and The Royal Pharmaceutical Society of Great Britain display 'Location' of the address provided by their registrants on the web. A few members of my team have been concerned about the GDC's practice and I have been corresponding with the GDC accordingly. I have become aware that this item is on the agenda of the Registration Committee's meeting to be held on 8 August 2007. The GDC informed me that they have only had a few concerns expressed on this issue; I informed them that there are rumblings in my region, but that people have not put this in writing to the GDC.

The GDC's Head of Registration Department, Mr J. Briden informed me that any further comments or suggestions on this issue should be submitted to him by 31 July 2007 so that he could take them to the meeting of 8 August.

The GDC, although there to protect the public, also have a duty of care to their registrants and I hope that the above will provide them food for thought.

\section{G. Krishnamoorthy}

\section{By email}

1. Guidance for doctors on using registered name and GMC Reference Numbers. General Medical Council, 2005

\section{doi: 10.1038/bdj.2007.651}

\section{Loss to the profession}

Sir, I was very sad to read that John Bates had passed away earlier this year (BDJ 2007; 202: 701). Derek Stafford's words were very poignant and described so accurately the Prof Bates that this former student remembers.

I found myself smiling as I thought back to my undergraduate days and to this very special teacher. I was one of those 'who regarded him with affection'. Derek Stafford is absolutely right. We were in awe of him. But we also knew that he always had our welfare uppermost in his mind - even if we didn't necessarily deserve it. It was he who kindled and encouraged my interest in removable prosthodontics.

Having passed finals, I was unsuccessful in securing a house officer position. To my surprise Prof summoned me to his office, ascertained that I wanted to stay in hospital and said he'd see what he could do. The next morning I was in Birmingham attending for interview in the dental school.

Over the years, I am sure that I was just one of many he helped in a similar way, but I shall be forever grateful to him.

The profession is poorer for his loss.

L. Cabot

London

doi: 10.1038/bdj.2007.652 